\title{
Communication \\ Efficient PbS Quantum Dot Solar Cells with Both Mg-Doped ZnO Window Layer and ZnO Nanocrystal Interface Passivation Layer
}

\author{
Hao Ren ${ }^{1}$, Ao Xu ${ }^{1}$, Yiyang Pan ${ }^{1}$, Donghuan Qin ${ }^{1, *}{ }^{\mathbb{D}}$, Lintao Hou ${ }^{2, *}$ and Dan Wang ${ }^{1}$ \\ 1 State Key Laboratory of Luminescent Materials \& Devices, Institute of Polymer Optoelectronic Materials \& \\ Devices, South China University of Technology, Guangzhou 510640, China; renhns@foxmail.com (H.R.); \\ m13856403915@163.com (A.X.); 201730321247@mail.scut.edu.cn (Y.P.); wangdan@scut.edu.cn (D.W.) \\ 2 Guangdong Provincial Key Laboratory of Optical Fiber Sensing and Communications, Guangzhou Key \\ Laboratory of Vacuum Coating Technologies and New Energy Materials, Siyuan Laboratory, \\ Department of Physics, Jinan University, Guangzhou 510632, China \\ * Correspondence: qindh@scut.edu.cn (D.Q.); thlt@jnu.edu.cn (L.H.)
}

Citation: Ren, H.; Xu, A.; Pan, Y.; Qin, D.; Hou, L.; Wang, D. Efficient PbS Quantum Dot Solar Cells with Both Mg-Doped ZnO Window Layer and $\mathrm{ZnO}$ Nanocrystal Interface

Passivation Layer. Nanomaterials 2021, 11, 219. https://doi.org/10.3390/ nano11010219

Received: 30 December 2020

Accepted: 13 January 2021

Published: 15 January 2021

Publisher's Note: MDPI stays neutral with regard to jurisdictional claims in published maps and institutional affiliations.

Copyright: (C) 2021 by the authors. Licensee MDPI, Basel, Switzerland. This article is an open access article distributed under the terms and conditions of the Creative Commons Attribution (CC BY) license (https:// creativecommons.org/licenses/by/ $4.0 /)$.

\begin{abstract}
In this paper, a Mg-doped $\mathrm{ZnO}(\mathrm{MZO})$ thin film is prepared by a simple solution process under ambient conditions and is used as the window layer for PbS solar cells due to a wide $\mathrm{n}$ type bandgap. Moreover, a thin layer of ZnO nanocrystals (NCs) was deposited on the MZO to reduce carrier recombination at the interface for inverted $\mathrm{PbS}$ quantum dot solar cells with the configuration Indium Tin Oxides (ITO)/MZO/ZnO NC (w/o)/PbS/Au. The effect of film thickness and annealing temperature of $\mathrm{MZO}$ and $\mathrm{ZnO} \mathrm{NC}$ on the performance of PbS quantum dot solar cells was investigated in detail. It was found that without the $\mathrm{ZnO} \mathrm{NC}$ thin layer, the highest power conversion efficiency(PCE) of $5.52 \%$ was obtained in the case of a device with an MZO thickness of 50 $\mathrm{nm}$. When a thin layer of ZnO NC was introduced between MZO and PbS quantum dot film, the PCE of the champion device was greatly improved to $7.06 \%$ due to the decreased interface recombination. The usage of the MZO buffer layer along with the $\mathrm{ZnO}$ NC interface passivation technique is expected to further improve the performance of quantum dot solar cells.
\end{abstract}

Keywords: Mg-doped $\mathrm{ZnO}$; PbS; quantum dot; solar cells

\section{Introduction}

$\mathrm{PbS}$ colloidal quantum dot (CQD) solar cells have been rapidly developed in recent years with a certified power conversion efficiency (PCE) up to $13 \%$ in an optimal device configuration [1,2]. Compared to traditional photovoltaic technology, PbS CQD solar cells show great potential applications in energy products in view of their low cost, low temperature, and simple solution processing techniques [3-10]. More importantly, the bandgap of PbS CQDs can be easily controlled by varying the size of the CQDs, which enables efficient harvesting of a broad light spectrum from the visible to infrared region. Thus, the fabrication of tandem cells can be easily achieved based on a single material [11-13].

The significant performance improvement of $\mathrm{PbS} C Q D$ solar cells is mainly attributed to the developing ligand exchange technique, interface engineering, and optimized device architecture. It is well known that PbS CQDs are usually capped by insulating ligands, such as oleic acid and oleic amine, during the synthesis processes. These insulating ligands will later become defects and carrier traps in the photovoltaic devices, which are mainly responsible for the low device performance [14,15]. Approaches to replace the insulating ligands must address the issues of the $\mathrm{Pb}^{2+}$ oxidation and the shortening of the distance between PbS CQDs. In previous work, 1,2-Ethanedithiol (EDT) or 3-Mercaptopropionic acid was selected as a short bidentate ligand to replace the insulating ligands during the device fabrication process and showed promising outcomes in reducing interparticle spacing and improving device performance [16-18]. Later, people found that the hydroxyl 
$(\mathrm{OH})$ groups attached to (111) facets of PbS nanocrystals will increase the trap states in the CQDs and limit device performance [19-21]. By combining metal halide and organic ligands, the density of dangling bonds and trap states can be reduced effectively and result in higher PCE [22-25]. Unfortunately, there are still some residual $\mathrm{OH}$ groups left behind during the ligand exchange process, which further impede the improvement of CQD solar cells. After exploring these challenges for several years, researchers have found some ways to overcome this difficulty. For instance, by adding $\mathrm{PbBr}_{2}$ during the synthesis process, the surface of PbS CQDs will reconstruct and the number of $\mathrm{OH}$ surface groups will be significantly reduced, which could improve the device PCE to a high level of $12.5 \%$ [26].

On the other hand, the electron transfer layers (ETLs) also have a significant effect on the CQD solar cells. Metal oxides, like titanium dioxide $\left(\mathrm{TiO}_{2}\right)$ and zinc oxide $(\mathrm{ZnO})$, are often used as the ETL for PbS CQD solar cells with inverted device architecture [27-30]. Because of their excellent electron transport properties and simple solution processing techniques, these metal oxides are promising candidates for ETLs in low-cost, efficient CQD solar cells. To improve the CQD solar cell performance, it is essential to increase the carrier mobility of ETLs and construct a preferable band alignment with the active layer. One path to control the electronic properties of ETLs is introducing metal (such as $\mathrm{Al}, \mathrm{Mg}$, $\mathrm{Sb}$, etc.) salt into a metal oxide precursor before the ETL film deposition. For example, Liu et al. [31] reported efficient $\mathrm{PbS} C Q D$ solar cells using $\mathrm{Zr}$-doped $\mathrm{TiO}_{2}$ electron-acceptor materials. By changing the doping density, the band structure of the $\mathrm{TiO}_{2}$ thin film was modified to enhance charge separation efficiency at the $\mathrm{CQD} / \mathrm{TiO}_{2}$ interface. In the case of $\mathrm{ZnO}$ ETLs, potential doping elements include indium, tin, aluminum, lithium, and other organic dopants [32-34]. Introducing double ETLs is another way to improve the carrier separation efficiency between ETLs and the PbS CQD active layer. Eisner et al. [35] adopted $\operatorname{In}_{2} \mathrm{O}_{3}$ (thin layer) $/ \mathrm{ZnO}$ as a double ETL for quantum dots or organic solar cells. Their devices showed enhanced electron mobility and a tunable Fermi level, which resulted in relatively low series resistance and improved PCE. In our previous work [36], we found that the performance of CdTe nanocrystal (NC) solar cells with an inverted structure of $\mathrm{FTO} / \mathrm{TiO}_{2} / \mathrm{CdTe} / \mathrm{Au}$ can be largely improved by inserting a thin layer of solution-processed CdS NC film between the $\mathrm{CdTe} \mathrm{NC}$ and $\mathrm{TiO}_{2}$ due to the optimized band alignment and p-n junction quality. The light absorption of the ETLs, however, might also negatively influence the device performance. Hu et al. [37] replaced the $\mathrm{ZnO}$ with a Mg-doped $\mathrm{ZnO}$ (MZO) layer to broaden the band gap of an ETL to reduce its parasitic absorption. By this method, more light is permitted to go through the ETL and is absorbed by the PbS CQD active layer.

Herein, we present a novel solution processed PbS CQD solar cell which adopts $\mathrm{MZO} / \mathrm{ZnO} \mathrm{NC}$ thin films as double ETLs. By adjusting the deposition conditions of the $\mathrm{ZnO} \mathrm{NC}$ thin film, behaviors of the $\mathrm{MZO} / \mathrm{PbS}$ interface are well controlled and a more compact nanocrystalline $\mathrm{PbS}$ film could be formed. Various characterizations were performed to inspect the surface morphology of the $\mathrm{MZO} / \mathrm{ZnO} \mathrm{NC}$ thin film for illustrating how these double ETLs help modify the $\mathrm{MZO} / \mathrm{PbS}$ interface. By introducing the double ETL strategy into solution processed PbS CQD solar cells, photovoltaic devices with an inverted structure of the ITO/MZO/ZnO NC film (w/o)/PbS CQDs/Au were fabricated. As the interface between the ETL and PbS CQD films was well controlled, traps at the interface are effectively eliminated and the device performance is greatly improved, which exhibited a high PCE of 7.09\%, while the value of the device without the ZnO NC film was $5.52 \%$. In conclusion, devices with double ETLs show almost 30\% improvements compared to the control device without the $\mathrm{ZnO} \mathrm{NC}$ layer. In addition, the results of constant measurement over 30 days indicated that these PbS CQD solar cells are extraordinarily stable under ambient preservation conditions. The simple environmentally friendly fabrication process surely makes the PbS CQD photovoltaic device a promising candidate for low-cost solar cell applications. 


\section{Experiment Procedure}

Materials: oleic acid (90\%), $\mathrm{PbO}(99.999 \%)$, bis(trimethylsilyl)sulfide ((TMS) ${ }_{2} \mathrm{~S}, 98 \%$ ), octadecene (ODE, 90\%), zinc acetate dehydrate, 2-methoxyethanol (99.8\%), ethanolamine, magnesium acetate tetrahydrate (99\%), ethanolamine (99.5\%), n-butanol, tetrabutylammonium iodide (TBAI, $99 \%)$, acetone (95\%), toluene (95\%), n-Hexane (99\%), methanol $(98 \%)$, ethanol (99.7\%), n-butanol (99.5\%), $\mathrm{KOH}(85 \%)$, 1,2-ethanedithiol (98\%), acetonitrile (99\%). All chemicals were used as received without further purification.

Preparation of Mg-doped $\mathrm{ZnO}(\mathrm{MZO})$ precursor: the precursor was prepared by mixing $785 \mathrm{mg}$ zinc acetate dihydrate, $97.7 \mathrm{mg}$ magnesium acetate tetrahydrate, $4.8 \mathrm{~mL} \mathrm{2-}$ methoxyethanol, and $0.2 \mathrm{~mL}$ ethanolamine together and stirring under $\mathrm{N}_{2}$ flow at $50{ }^{\circ} \mathrm{C}$ for $24 \mathrm{~h}$. The precursor was then cooled down to room temperature and sealed in glass bottles.

Synthesis of $\mathrm{ZnO}$ nanoparticles: the $\mathrm{ZnO}$ nanoparticles were synthesized according to the literature [16] with a modified recipe. An amount of $0.9788 \mathrm{~g}$ of zinc acetate dihydrate was added to $42 \mathrm{~mL}$ methanol in a three-neck flask. The mixtures were heated to about $60{ }^{\circ} \mathrm{C}$ under $\mathrm{N}_{2}$ flow. Then $0.469 \mathrm{~g} \mathrm{KOH}$ was dissolved in $22 \mathrm{~mL}$ methanol and added dropwise to the solution. The resulted mixture was continuously stirred for $1.5 \mathrm{~h}$ at $62{ }^{\circ} \mathrm{C}$ and cooled down to room temperature. Finally, the ZnO NCs were collected by centrifuging and washing the mixture with methanol twice and dissolved into n-butanol with concentrations of $2.5-20 \mathrm{mg} / \mathrm{mL}$.

Synthesis of PbS CQDs: the synthesis method can be found in the literature [16,17]. In a typical process, $0.47 \mathrm{~g}$ of $\mathrm{PbO}, 1.35 \mathrm{~mL}$ of oleic acid, and $12.7 \mathrm{~mL}$ of ODE were mixed and loaded into a $100 \mathrm{~mL}$ three-neck flask, and then degassed at $100{ }^{\circ} \mathrm{C}$ for $2 \mathrm{~h}$ under vacuum and transferred to $\mathrm{N}_{2}$ flow. The mixture was heated up to $130^{\circ} \mathrm{C}$. Two hundred and ten microliters of (TMS) ${ }_{2} \mathrm{~S}$ were dissolved in $6.4 \mathrm{~mL}$ ODE and the mixture was rapidly injected into the solution in the three-neck flask. After $20 \mathrm{~s}$, the reaction was quenched by soaking the flask in an ice bath. The PbS CQDs were then purified by centrifuging in acetone, toluene, and ethanol in sequence. Finally, the PbS CQDs were dispersed into n-hexane at a concentration of $40 \mathrm{mg} / \mathrm{mL}$.

\section{Results and Discussion}

The PbS CQD solar cells with an inverted structure of ITO/MZO/ZnO NC (w/o)/PbS CQDs/Au were fabricated via a layer-by-layer solution process at room temperature under ambient conditions, as shown in Figure 1. Firstly, the ITO substrates were cleaned by acetone and treated by $\mathrm{O}_{2}$ plasma for $10 \mathrm{~min}$ before the deposition of the active layer. The MZO thin film was prepared by spin-coating the MZO precursor on the ITO substrate at $3000 \mathrm{rpm}$ for $20 \mathrm{~s}$ under ambient conditions, and annealed at $300{ }^{\circ} \mathrm{C}$ for $30 \mathrm{~min}$ on a hotplate. A thin layer of $\mathrm{ZnO}$ NC film was obtained by spin-coating the $\mathrm{ZnO}$ NC solution (with concentrations ranging from $2.5 \mathrm{mg} / \mathrm{mL}$ to $20 \mathrm{mg} / \mathrm{mL}$ ) on the ITO/MZO substrate at $3000 \mathrm{rpm}$ for $20 \mathrm{~s}$. The ITO/MZO/ZnO NC samples were then annealed at $100{ }^{\circ} \mathrm{C}$ for 5 min to eliminate any organic solvents. Since the size of $\mathrm{ZnO} N C$ s is similar to that of $\mathrm{PbS}$ CQDs, we can decrease the misfit dislocations caused by the large lattice mismatch between the $\mathrm{MZO}$ and $\mathrm{PbS}$ CQDs, and obtain low dangling bond densities at the interface with the insertion of the $\mathrm{ZnO}$ NC layer. Upon this ITO/MZO/ZnO NC substrate, eight layers of TBAI-treated PbS CQDs and two layers of EDT-treated PbS CQDs were deposited in sequence. This whole device fabrication process can be found in the literature [16]. During the device fabrication, oleic acid (OA) capped PbS CQDs was replaced by TBAI or EDT, and the treatment does not change the absorption of the PbS CQD thin film but reduces the distance between PbS CQDs and the Fermi energy level. The final products were stored in air overnight for further oxidation and sequentially annealed at $80^{\circ} \mathrm{C}$ for $10 \mathrm{~min}$. Finally, a $100 \mathrm{~nm}$ thick Au layer was deposited on the ITO/MZO/ZnO NC/PbS CQDs by vacuum evaporation through a shadow mask that defined an active area of $5.70 \mathrm{~mm}^{2}$ (as shown in Figure S1). 


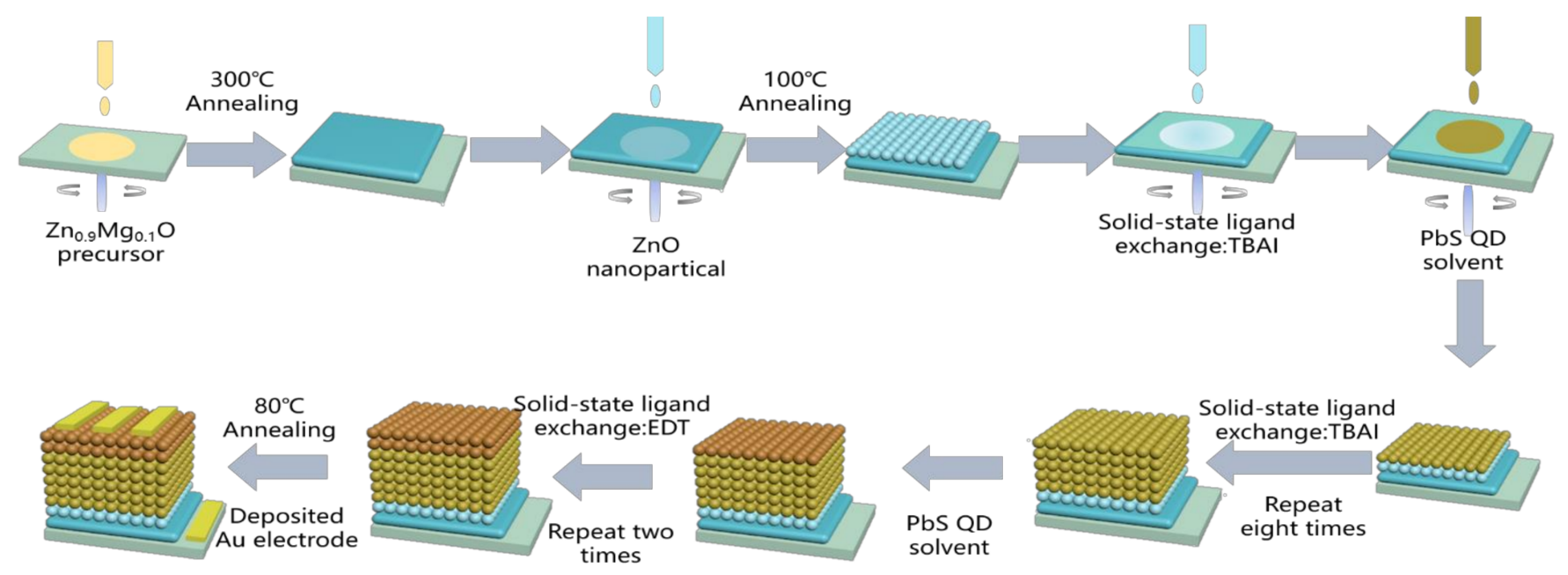

Figure 1. A schematic of $\mathrm{PbS}$ colloidal quantum dot (CQD) solar cell fabrication process under ambient conditions using layer-by-layer solution process.

The UV absorption spectrum of PbS CQDs is presented in Figure 2a. It was clear that the absorption peak was located at $920 \mathrm{~nm}$, corresponding to a bandgap of $1.35 \mathrm{eV}$. An X-ray diffraction (XRD) test was performed to investigate the crystal structure of the as-prepared MZO films. As shown in Figure 2b, when annealing at a low temperature, no peaks can be detected from the curve, which implies the formation of an amorphous structure under this treatment condition, which is consistent with results reported before [31]. As for the samples annealed at a higher temperature $\left(300^{\circ} \mathrm{C}\right)$, we could find diffraction peaks located at $31.9^{\circ}, 34.3^{\circ}$, and $36.2^{\circ}$, corresponding to the (100), (002), and (101) facets of wurtzite $\mathrm{ZnO}$ $\left(31.75^{\circ}, 34.44^{\circ}, 36.25^{\circ}\right)$. It is evident that there is a preferred growth orientation along the c-axis of $\mathrm{ZnO}$, as the (002) peak is the strongest. Compared to the $\mathrm{ZnO}$ film, the (002) peak of the $\mathrm{MZO}$ is shifted to a larger angle, which is due to the substitution of $\mathrm{Zn}^{2+}$ by small $\mathrm{Mg}^{2+}$, leading to a reduced crystal lattice parameter [21,22,31]. The transmission spectra of the $\mathrm{MZO}(\mathrm{ITO} / \mathrm{MZO})$ treated with different annealing temperatures and the $\mathrm{ZnO}$ thin film are shown in Figure 2c. The MZO thin film annealed at $300{ }^{\circ} \mathrm{C}$ can block the light with a wavelength shorter than $\sim 400 \mathrm{~nm}$ and was almost transparent for wavelengths $>400 \mathrm{~nm}$. In other words, $\mathrm{MZO}$ thin films are nearly transparent for visible light. At a lower annealing temperature $\left(200^{\circ} \mathrm{C}\right)$, the transmission is significantly lower than that of a higher annealing temperature $\left(300{ }^{\circ} \mathrm{C}\right)$, which may be a consequence of the incomplete crystallization of $\mathrm{MZO}$. From the plots of $(a h v)^{2}$ versus the photon energy (Figure $2 \mathrm{~d}$ ), all the curves have a linear onset, indicating the existence of a direct bandgap. By extrapolating the linear region of these curves to intersection with the $x$-axis, we could determine that the bandgaps for the $\mathrm{MZO}$ thin film with different annealing temperatures were $3.43 \mathrm{eV}$ and $3.44 \mathrm{eV}$, respectively, while this value was $3.25 \mathrm{eV}$ for the $\mathrm{ZnO}$ thin film. 

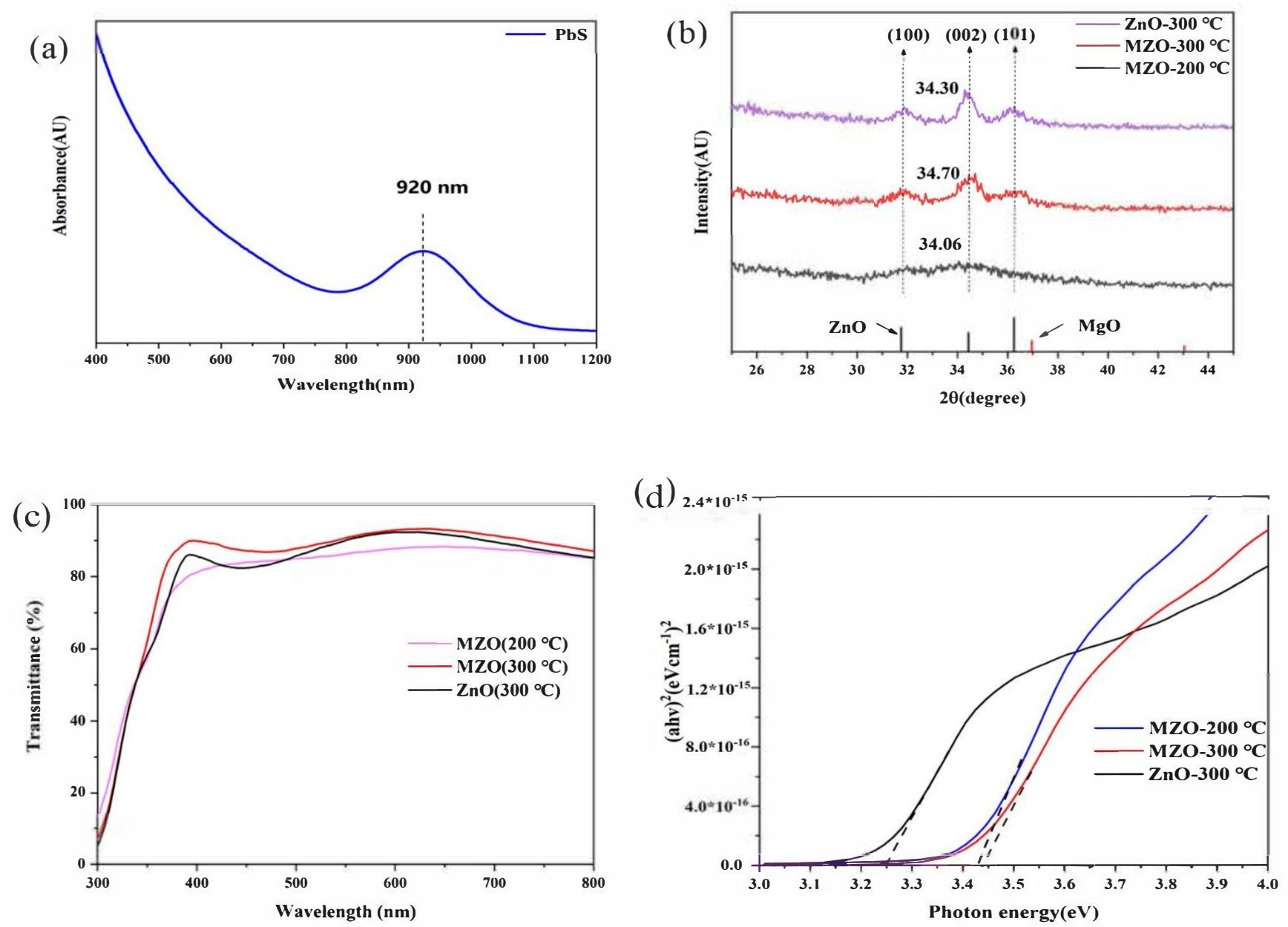

Figure 2. (a) Absorbance spectra of PbS CQDs for all devices listed here. (b) XRD pattern of $\mathrm{ZnO}$ and Mg-doped $\mathrm{ZnO}$ (MZO) thin films. (c) The transmission spectra of $\mathrm{MZO}$ with low annealing temperature $\left(200^{\circ} \mathrm{C}\right)$ and high annealing temperature $\left(300{ }^{\circ} \mathrm{C}\right.$ ) and undoped $\mathrm{ZnO}$ thin film annealed at $300{ }^{\circ} \mathrm{C}$. (d) The plots of $(a h v)^{2}$ versus photon energy for $\mathrm{MZO}$ and $\mathrm{ZnO}$ thin films.

The MZO is a good ETL for PbS CQD solar cells due to the high transparency and high conduction band. To ascertain the optimal temperature and thickness of the $\mathrm{PbS}$ CQD active layer and MZO ETL for solar cells, devices with an inverted structure of $\mathrm{ITO} / \mathrm{MZO} / \mathrm{PbS} / \mathrm{Au}$ were fabricated by depositing six PbS CQD layers on MZO film. A control device with $\mathrm{ZnO}$ ETL was also fabricated with the same conditions. It is obvious that an appropriate annealing temperature and thickness of MZO are necessary to obtain high-quality ETL thin films [31]. The current density-voltage characterization under dark conditions or $100 \mathrm{~mW} \mathrm{~cm}{ }^{-2}$ (AM 1.5G) illumination (the irradiation area is $100 \mathrm{~cm}^{2}$ ) with a solar simulator (XES-40S1, SAN-EI electric) was carried out on a computer-controlled Keithley 2400 Source Meter system in ambient conditions. The $J-V$ curves of PbS CQD solar cells with different annealing temperatures and thicknesses are presented in Figure $3 a, b$, and the photovoltaic performance is summarized in Table 1. To figure out the effects of annealing temperature on CQD device performance, the thickness of MZO is fixed at $50 \mathrm{~nm}$ for all cases. The devices with MZO annealed at a temperature of $300{ }^{\circ} \mathrm{C}$ showed the highest efficiency of $4.94 \%$ with a short circuit current density $\left(J_{\mathrm{sc}}\right)$ of $22.44 \mathrm{~mA} / \mathrm{cm}^{2}$, an open circuit voltage $\left(V_{\mathrm{oc}}\right)$ of $0.55 \mathrm{~V}$, and a fill factor $(\mathrm{FF})$ of $39.75 \%$. On the other hand, the devices annealed at a low temperature exhibited the lowest PCE $(4.32 \%)$ due to the reduction of $J_{\mathrm{sc}}$. Increasing the annealing temperature further to over $350^{\circ} \mathrm{C}$ also leads to a decrease in device performance because of the increase in series resistance, which has been 
confirmed previously [38]. We further investigated the effect of MZO thickness on the CQD device performance. In this case, the annealing temperature for MZO layers in the device is set to be $300{ }^{\circ} \mathrm{C}$, while the thickness of the MZO layers is varied by changing the rate of spin-coating and the concentration of the MZO precursor. As shown in Figure $3 b$, the champion devices with $50 \mathrm{~nm}$ MZO showed the highest efficiency of $5.52 \%$, with a short circuit current density $\left(J_{\mathrm{sc}}\right)$ of $23.37 \mathrm{~mA} / \mathrm{cm}^{2}$, an open circuit voltage $\left(V_{\mathrm{oc}}\right)$ of $0.54 \mathrm{~V}$, and a fill factor (FF) of $43.47 \%$. The devices with an MZO thickness greater or less than $50 \mathrm{~nm}$ showed poor performance. As a result, we adopt $300{ }^{\circ} \mathrm{C}$ as the annealing temperature and $50 \mathrm{~nm}$ MZO for all the devices discussed below.
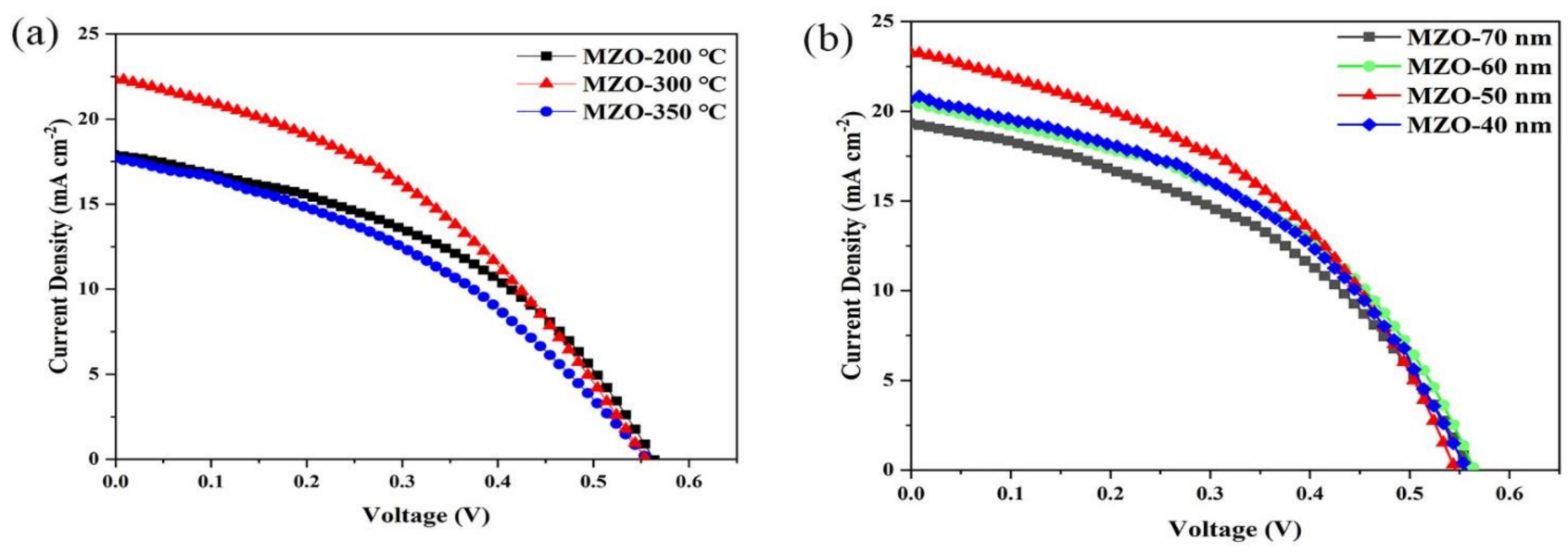

Figure 3. $J-V$ characteristics of ITO/Mg-doped $\mathrm{ZnO}(\mathrm{MZO}) / \mathrm{PbS}$ CQDs / Au devices with (a) different annealing temperatures and (b) MZO thicknesses.

Table 1. Summarized photovoltaic parameters from $J-V$ curves (Figure 3a,b) of PbS CQD solar cells prepared under different conditions.

\begin{tabular}{cccccc}
\hline $\begin{array}{c}\text { Annealing } \\
\text { Temperature }\left({ }^{\circ} \mathbf{C}\right)\end{array}$ & $\begin{array}{c}\text { MZO Layer } \\
\text { Thickness (nm) }\end{array}$ & $\boldsymbol{V}_{\boldsymbol{o c}}(\mathbf{V})$ & $J_{\boldsymbol{s c}}\left(\mathbf{m A} \mathbf{\mathbf { c m } ^ { \mathbf { 2 } } )}\right.$ & $\mathbf{F F}(\mathbf{\%})$ & PCE (\%) \\
\hline 200 & 50 & 0.56 & 17.79 & 43.15 & 4.32 \\
300 & 50 & 0.55 & 22.44 & 39.75 & 4.94 \\
350 & 50 & 0.55 & 17.62 & 39.04 & 3.81 \\
300 & 40 & 0.55 & 20.67 & 44.74 & 5.12 \\
300 & 50 & 0.54 & 23.37 & 43.47 & 5.52 \\
300 & 60 & 0.53 & 21.29 & 45.33 & 5.15 \\
300 & 70 & 0.56 & 19.33 & 44.23 & 4.82 \\
\hline
\end{tabular}

Since the high conduction band value of the MZO layer may prevent electrons being extracted from the active layer and lead to local carrier recombination, we introduced a thin layer of $\mathrm{ZnO}$ NC ( 10-34 nm) between the MZO and PbS CQDs. To deposit ZnO NC film on ITO/MZO substrates, $\mathrm{ZnO}$ NC solution (ZnO NCs dissolved in n-butanol) with different concentrations (the thicknesses of the corresponding $\mathrm{ZnO}$ NC layers were $10 \mathrm{~nm}$, $15 \mathrm{~nm}, 20 \mathrm{~nm}, 30 \mathrm{~nm}, 34 \mathrm{~nm}$ in $2.5 \mathrm{mg} / \mathrm{mL}, 5 \mathrm{mg} / \mathrm{mL}, 10 \mathrm{mg} / \mathrm{mL}, 15 \mathrm{mg} / \mathrm{mL}, 20 \mathrm{mg} / \mathrm{mL}$, respectively) was spin-coated onto the substrates and annealed at $100{ }^{\circ} \mathrm{C}$ to remove any organic solvents. Atomic force microscopy (AFM) was used to characterize the surface morphology of ITO/MZO/ZnO NC samples with different thicknesses of ZnO NCs. As shown in Figure $4 \mathrm{a}-\mathrm{f}$, all samples showed very smooth surfaces with root mean square (RMS) values below $4 \mathrm{~nm}$ (the corresponding RMS values are $2.01 \mathrm{~nm}, 3.61 \mathrm{~nm}, 3.17 \mathrm{~nm}$, $2.43 \mathrm{~nm}, 1.81 \mathrm{~nm}$, and $1.82 \mathrm{~nm}$ ). It was noted that the RMS values for 10 and $15 \mathrm{~nm}$ thick $\mathrm{ZnO}$ NC layers are 3.61 and $3.17 \mathrm{~nm}$, respectively, significantly higher than other $\mathrm{ZnO} \mathrm{NC}$ samples, which may be due to the insufficiency of ZnO NCs to fully cover the substrate at a low $\mathrm{ZnO}$ NC concentration. The smoothness of the $\mathrm{ZnO}$ NC surface is essential to promote 
the physical contact conditions between $\mathrm{ZnO}$ NCs and PbS CQDs and reduce interfacial recombination, and to improve device performance.

(a)

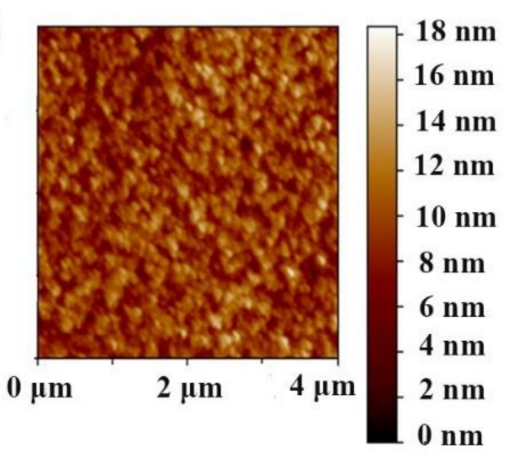

(d)

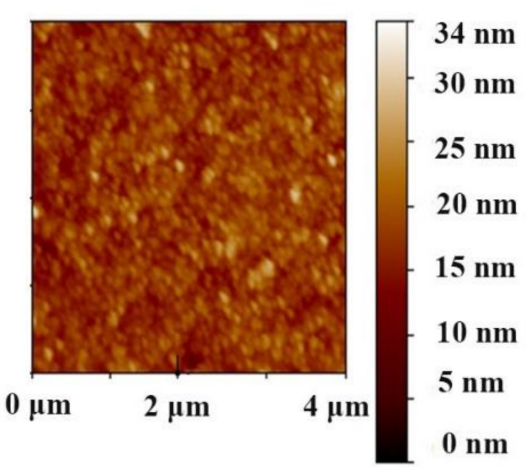

(b)

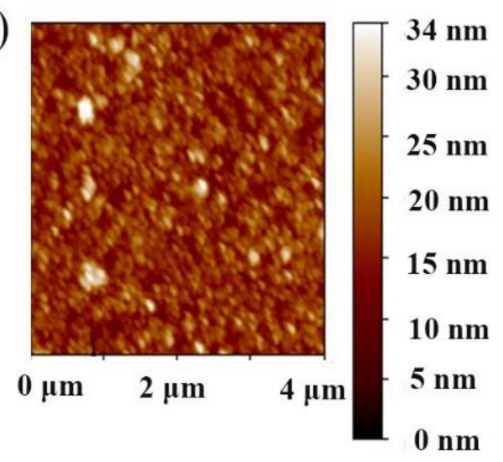

(e)

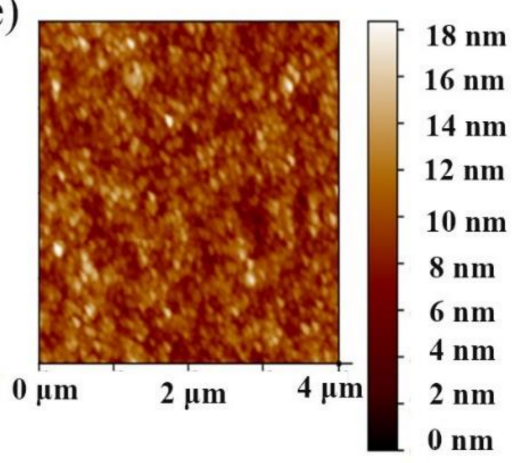

(c)

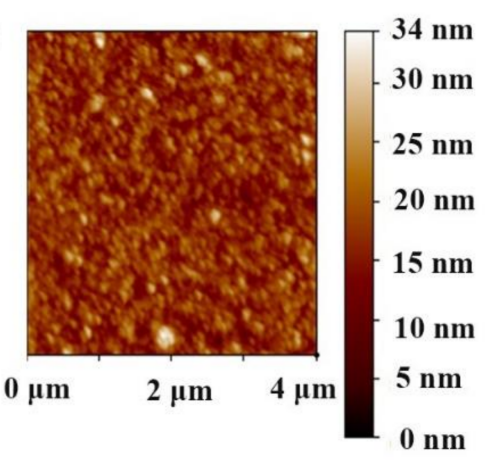

(f)

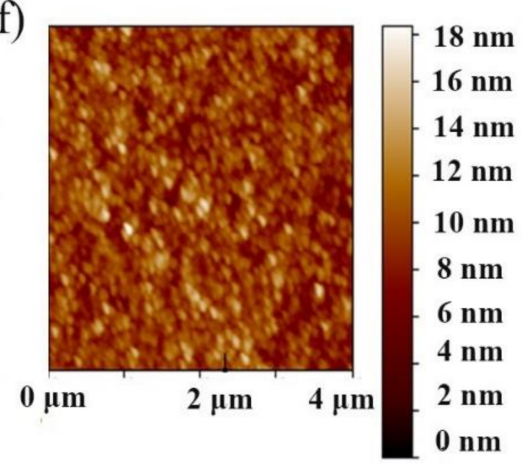

Figure 4. Atomic force microscopy (AFM) images of ITO/Mg-doped $\mathrm{ZnO}$ (MZO)/ZnO nanocrystals (NCs) (prepared by spin-casting $\mathrm{ZnO} N C$ solution onto the ITO/MZO substrate with different NC concentrations) with different thicknesses of ZnO NCs of (a) 0, (b) 10, (c) 15, (d) 20, (e) 30, and (f) $34 \mathrm{~nm}$.

Now let us focus on the influence of the introduction of the $\mathrm{ZnO} N C$ thin film with different thicknesses on photovoltaic device performance. As we have just discussed, a $\mathrm{ZnO} \mathrm{NC}$ thin film with an appropriate thickness is essential to eliminate interface defects and improve device performance. Figure $5 \mathrm{a}, \mathrm{b}$ show the device structure and cross-section scanning electron microscopic (SEM) images of PbS CQD solar cells. From the SEM images, one can see that the ETLs $(\sim 70 \mathrm{~nm})$ and PbS CQD $(\sim 300 \mathrm{~nm})$ active layers are compact and there are no pinholes in a large area. The energy dispersive X-ray spectroscopy (EDS) spectrum presented in Figure S2 shows that the ratio between $\mathrm{Pb}$ and $\mathrm{S}$ is near $1: 1$, indicating the total conversion of $\mathrm{S}$ to $\mathrm{PbS}$ during the reaction. For this part of the research, the thickness of $\mathrm{ZnO} \mathrm{NC}$ film was varied from 0 to $34 \mathrm{~nm}$, whereas the thicknesses of the MZO and PbS CQD films were fixed at 50 and $300 \mathrm{~nm}$, respectively, with the device structures of ITO/MZO/ZnO NC/PbS/ Au. In other words, all the experimental parameters were fixed except the thickness of $\mathrm{ZnO} N C$. The PCEs with and without $\mathrm{ZnO}$ NCs are presented in Figure $5 \mathrm{c}$. The $J-V$ curves for different $\mathrm{ZnO}$ NC thicknesses under light are presented in Figure S2 and the dark J-V curves are presented in Figure S3. The detailed photovoltaic parameters are summarized in Table 2. It should be noted that the PCEs of PbS CQD solar cells increase with $\mathrm{ZnO}$ NCs from 15 to $20 \mathrm{~nm}$, and experience a degradation as the thickness of the $\mathrm{ZnO} N C$ layer exceeds $20 \mathrm{~nm}$. The optimal PCE is obtained in the $15 \mathrm{~nm}$ $\mathrm{ZnO} N C$ device, which shows the following merits: a $J_{\mathrm{sc}}$ of $26.72 \mathrm{~mA} / \mathrm{cm}^{2}$, a $V_{\mathrm{oc}}$ of $0.56 \mathrm{~V}$, an FF of $47.12 \%$, and a PCE of $7.09 \%$. Meanwhile, the control device with a single MZO as an ETL exhibits a $V_{\text {oc }}$ of $0.54 \mathrm{~V}$, a $J_{\mathrm{sc}}$ of $23.36 \mathrm{~mA} / \mathrm{cm}^{2}$, and an FF of $43.47 \%$, resulting in a PCE of $5.52 \%$. As a result, the optimal PCE value is 30\% higher than that of the control device. For a device with a $\mathrm{ZnO}$ NC layer thickness of less than $15 \mathrm{~nm}$, it is anticipated that interface recombination will occur because of the inadequate coverage of the MZO 
film. Moreover, when the $\mathrm{ZnO}$ NC layer is too thick, the series resistance will increase, which leads to low FF and PCE. The external quantum efficiency (EQE) spectra shown in Figure $5 \mathrm{~d}$ provide insights for understanding how the $J_{\mathrm{sc}}$ of the devices was affected by the $\mathrm{ZnO}$ NC layer. In comparison to a device without ZnO NCs, the EQE spectrum of the $\mathrm{ZnO} \mathrm{NC}$ device exhibits a high carrier extraction rate in the wavelength range from 400 to $900 \mathrm{~nm}$, suggesting an enhanced carrier collection with the help of a ZnO NC interlayer since the interface defects can be effectively eliminated. The integrated current densities of $25 \mathrm{~mA} / \mathrm{cm}^{2}$ and $22 \mathrm{~mA} / \mathrm{cm}^{2}$ are obtained from EQE curves, which are consistent with our $J-V$ measurement (Figure $5 c$ ). We noted that the FF of optimized PbS CQD solar cells is less than 50\%, which implies that high series resistance and low parallel resistance existed in CQD solar cells. We speculate that although the introduction of $\mathrm{ZnO}$ NCs improves the FF and PCE of PbS CQD solar cells, carrier recombination will still occur in the active layer and the $\mathrm{ZnO} / \mathrm{PbS}$ interface as the devices are fabricated under ambient conditions. The experimental conditions, such as humidity, temperature, and cleanliness, should be well controlled to further improve the performance of PbS CQD solar cells. It should be pointed out that the device stability is one of the major issues for PbS CQD solar cells. We examined the stability of NC solar cells by testing the device performance preserved under ambient conditions at intervals of several days over a relatively long period. In our CQD solar cell configuration, the stability is mainly related to the quality of the $\mathrm{PbS} \mathrm{CQD} / \mathrm{ZnO}$ $\mathrm{NC}$ interface, the PbS CQD active layer, and the contact electrode. As shown in Figure 5e,f, the PCE, $J_{\mathrm{Sc}}$, and $V_{\mathrm{oc}}$ reach their maximum value at day 7 , which then remained almost unchanged after preservation under ambient conditions for 30 days. The increase in device performance after 7 days may be due to the reduced interface recombination between CQDs and the CQD/Au interface, which was also confirmed in the literature [39]. The device with an MZO/ZnO NC ETL maintained 97.7\% of its maximum PCE after being placed in ambient conditions for such a period. We speculate that the introduction of a $\mathrm{ZnO} \mathrm{NC}$ layer might also benefit the stability of CQD solar cells.

(a)

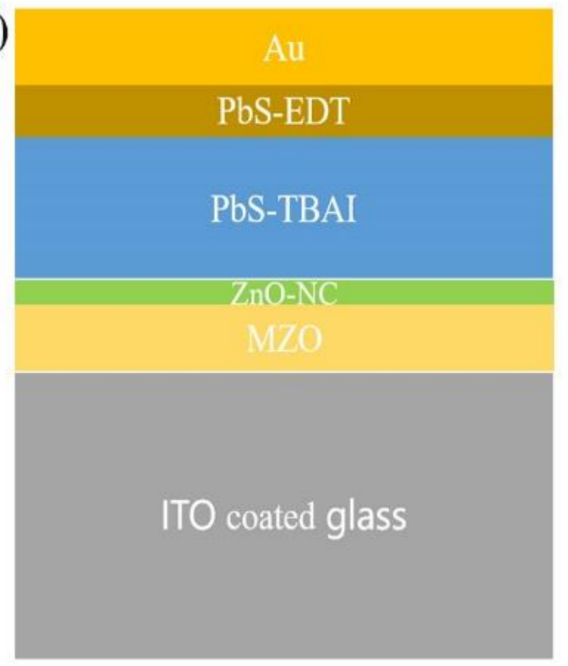

(b)

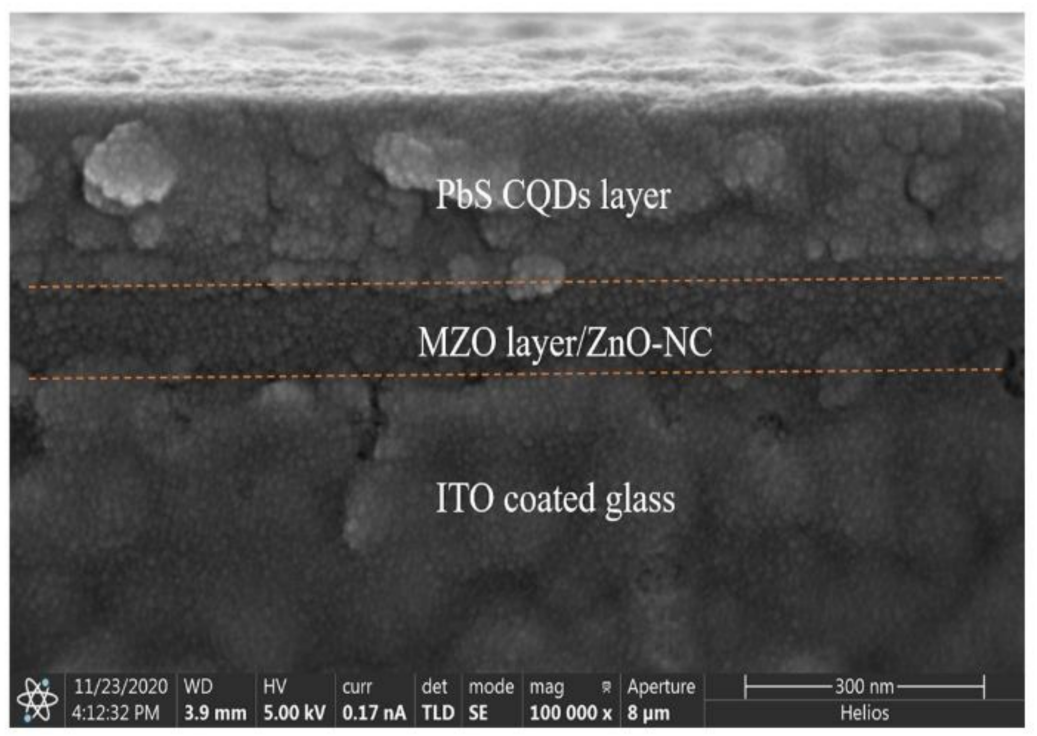

Figure 5. Cont. 

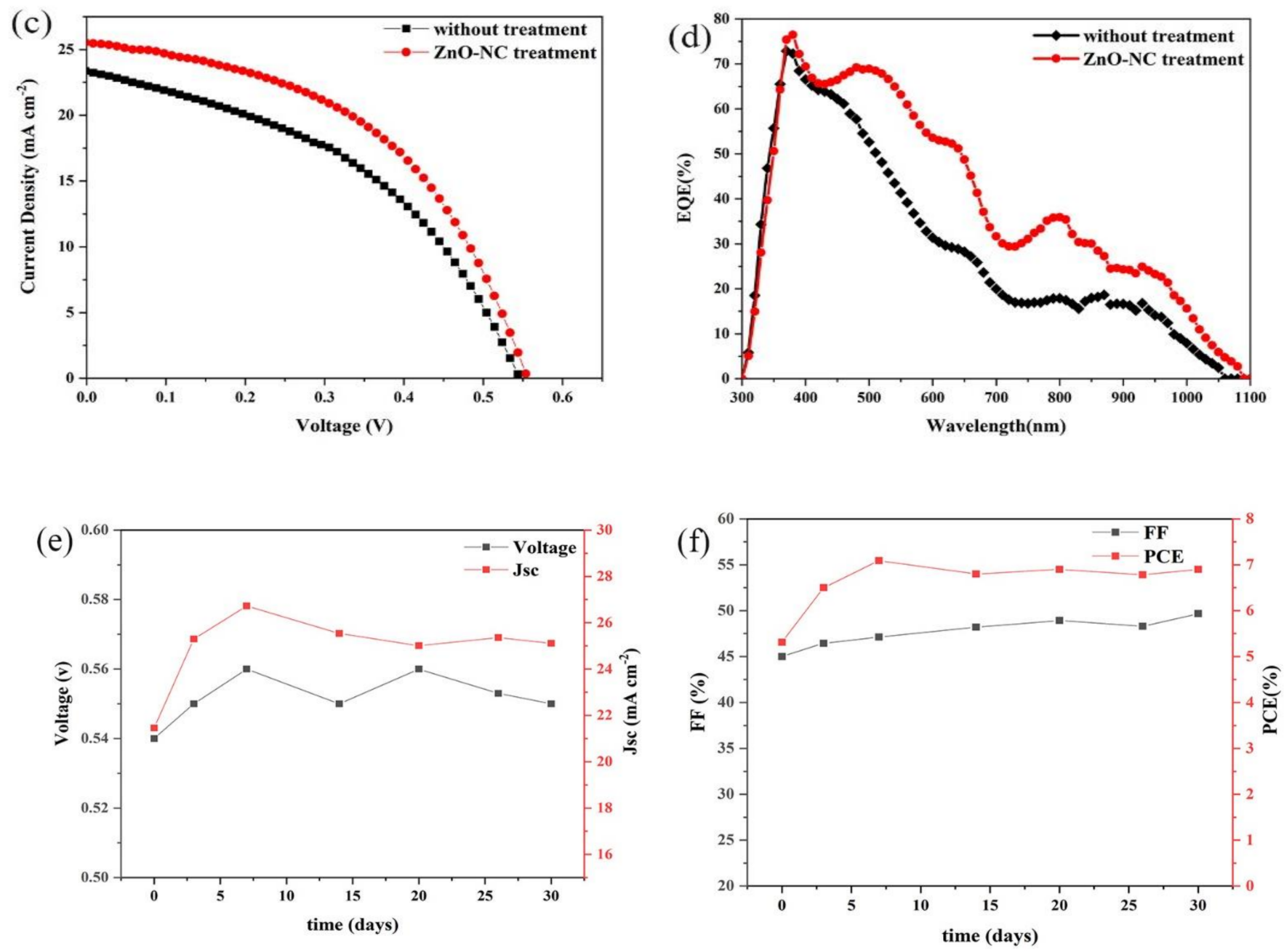

Figure 5. (a) The device structure of CQD solar cells, (b) cross-section SEM image of ITO/Mg-doped ZnO(MZO)/ZnO NC/PbS CQD thin film. (c) The $J-V$ curves for optimized PbS CQD solar cells with and without ZnO NCs, and corresponding (d) EQE spectra. Stability test of CQD solar cells (e) $V_{o c}$ and Jsc and (f) FF and PCE; devices are stored under ambient conditions and all devices are encapsulated.

Table 2. Summarized photovoltaic parameters of PbS CQD solar cells prepared with different $\mathrm{ZnO}$ NC thicknesses (device structure: ITO/Mg-doped ZnO (MZO)/ZnO NC/PbS CQDs/Au).

\begin{tabular}{|c|c|c|c|c|c|c|}
\hline ZnO NC Layer Thickness (nm) & $V_{o c}(\mathrm{~V})$ & $J_{s c}\left(\mathrm{~mA} / \mathrm{cm}^{2}\right)$ & FF (\%) & PCE (\%) & $\begin{array}{c}R_{S} \\
\left(\Omega \mathrm{cm}^{2}\right)\end{array}$ & $\begin{array}{c}R_{s h} \\
\left(\Omega \mathrm{cm}^{2}\right)\end{array}$ \\
\hline 0 & 0.54 & 23.36 & 43.47 & 5.52 & 7.98 & 73.59 \\
\hline 10 & 0.54 & 22.87 & 40.02 & 4.97 & 10.61 & 71.82 \\
\hline 15 & 0.56 & 26.72 & 47.12 & 7.09 & 6.59 & 134.51 \\
\hline 20 & 0.56 & 25.01 & 48.9 & 6.9 & 5.56 & 129.83 \\
\hline 30 & 0.53 & 24.70 & 44.40 & 5.85 & 7.09 & 88.293 \\
\hline 34 & 0.56 & 23.49 & 47.43 & 6.09 & 6.97 & 80.028 \\
\hline
\end{tabular}

$R_{s}$ : Series resistance; $R_{s h}:$ parallel resistance.

To understand the influence of $\mathrm{ZnO}$ decoration on the PbS CQD device performance comprehensively, we measured the work function of the $\mathrm{MZO}$ and $\mathrm{MZO} / \mathrm{ZnO} \mathrm{NC}$ thin film by a Kelvin probe microscope. The Fermi levels of the MZO and MZO/ZnO NC are $4.49 \mathrm{eV}$ and $4.37 \mathrm{eV}$, respectively. It can be seen that the introduction of $\mathrm{ZnO}$ NCs increased the Fermi level of the MZO thin film. The band diagram of ITO, MZO, ZnO NCs, PbS CQDs, and $\mathrm{Au}$ is presented in Figure 6a. As expected, the introduction of $\mathrm{ZnO}$ NCs increased the 
Fermi level, which is beneficial to the electron injection from CQDs to the ETL. Moreover, as the conduction band of $\mathrm{ZnO} N C s$ is almost the same as that of PbS CQDs, the small energy barrier at the interface will decrease carrier recombination. We measured the $J-V$ characteristic of our device under dark conditions. As shown in Figure 6b, the current at the reversed bias for the device with a $\mathrm{ZnO} N C$ interlayer is almost one order lower than that of the device without a $\mathrm{ZnO} N C$ interlayer. The low leakage current implies that the $\mathrm{ZnO} N \mathrm{NC}$ interlayer can decrease the PbS CQDs/MZO interface defects and restrain carrier recombination, resulting in a significant improvement in device performance. To further illustrate the effects of the $\mathrm{ZnO} \mathrm{NC}$ interlayer on the recombination process of $\mathrm{PbS}$ CQD solar cells, the transient photovoltage (TPV) is used to measure the charge recombination in PbS CQD solar cells with/without a $\mathrm{ZnO}$ NC interlayer. In this measurement, a steady state equilibrium is obtained when the NC solar cells are placed under a white light bias and additional charges are generated by applying another weak laser pulse. As shown in Figure $6 c$, the charge recombination is characterized by tracking the transient voltage associated with the perturbations in the charge population. The charge recombination times for NC devices with/without a $\mathrm{ZnO} N C$ interlayer are $67.9 \mu$ s and $24.6 \mu \mathrm{s}$, respectively, which imply a lower charge recombination rate in the $\mathrm{ZnO} \mathrm{NC}$ interlayer device compared to devices without a $\mathrm{ZnO} \mathrm{NC}$ interlayer.
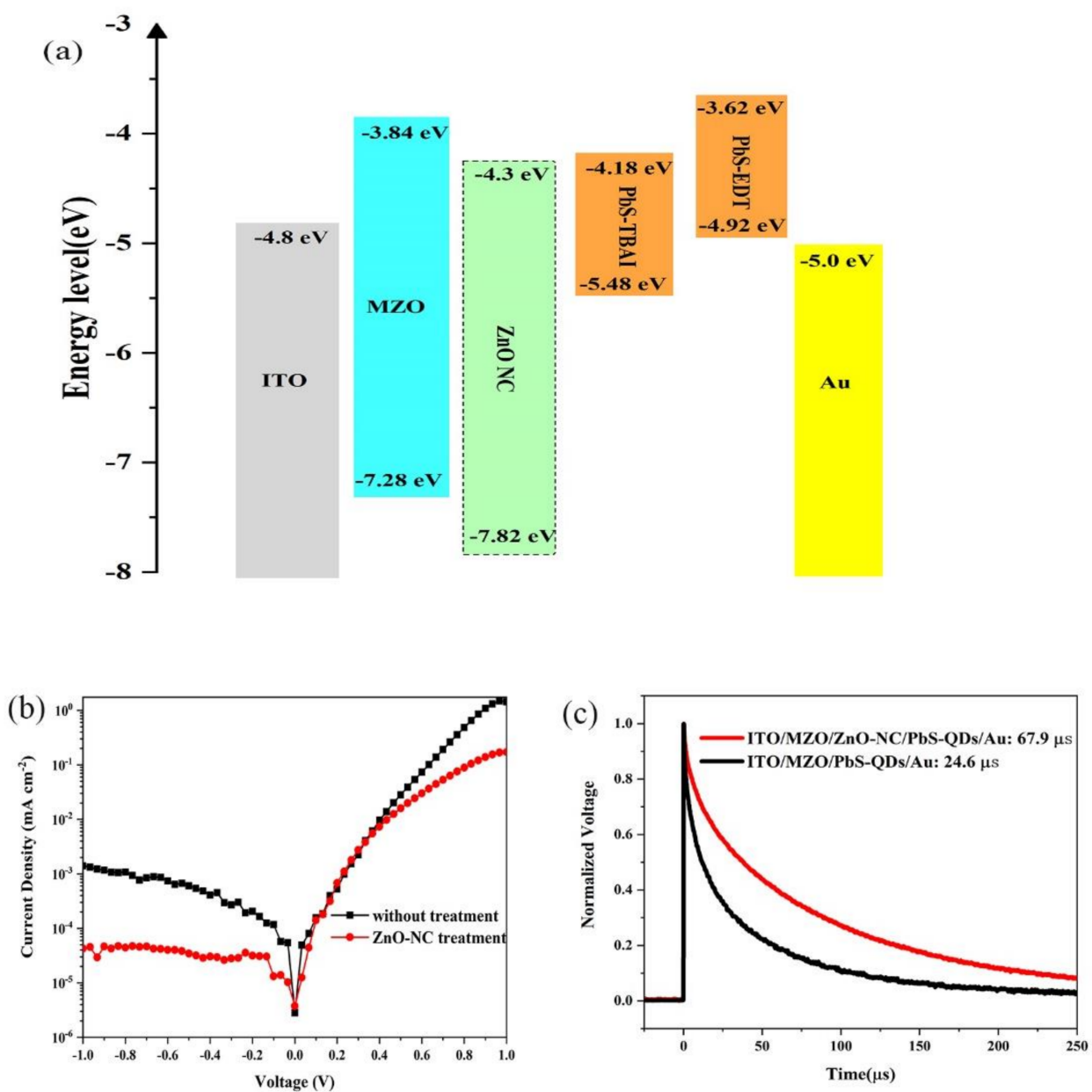

Figure 6. (a) The band alignment of PbS CQD solar cells with inverted structure of ITO/Mgdoped $\mathrm{ZnO}$ (MZO)/ZnO NC/PbS-TBAI/PbS-EDT/Au. (b) Dark $J-V$ curves of PbS CQD solar cells with/without $\mathrm{ZnO}$ NC layer. (c) Transient photovoltage (TPV) measurements of PbS solar cells with/without ZnO NC layer. 


\section{Conclusions}

In conclusion, we have fabricated efficient $\mathrm{PbS} \mathrm{CQD} / \mathrm{ZnO}$ heterojunction solar cells by a simple layer-by-layer solution process at ambient conditions. The introduction of an $\mathrm{MZO}$ window layer and a thin interfacial layer of $\mathrm{ZnO}$ NCs between the PbS CQDs and $\mathrm{MZO}$ could promote a band alignment condition and reduce interface defects. Compared to control devices, obvious improvements in $J_{\mathrm{sc}}$ and PCE are observed for devices with a $\mathrm{ZnO} \mathrm{NC}$ interlayer. After carefully optimizing the fabrication parameters, we obtained a device with a PCE of 7.09\%, which shows a 30\% increase compared to the control device. Our work here provides a new way to improve the performance of PbS CQD solar cells and might throw light on the industrial application of CQD solar cells.

Supplementary Materials: The following are available online at https:/ /www.mdpi.com/2079-4 991/11/1/219/s1, Figure S1: The photo of a real PbS CQD solar cell. In the cathode part, the $\mathrm{MZO} / \mathrm{ZnO} \mathrm{NC} / \mathrm{PbS}$ active layer has been scraped away before Au deposition. The active area is $0.057 \mathrm{~cm} 2$ for each device. Figure S2: SEM image and energy dispersive X-ray spectroscopy of ITO/MZO/ZnO-NC/PbS CQDs, Figure S3: J-V curves for PbS CQD solar cells with different ZnO NC layer thicknesses, Figure S4: dark J-V curves for PbS CQD solar cells with different ZnO NC layer thicknesses.

Author Contributions: D.Q. and H.R. conceived and designed the experiments; H.R., A.X. performed the experiments; H.R. and Y.P. analyzed the data; L.H., D.W. contributed reagents/materials/analysis tools; D.Q. and H.R. wrote the paper. All authors have read and agreed to the published version of the manuscript.

Funding: This research received no external funding.

Acknowledgments: We thank the financial support of the National Natural Science Foundation of China (Nos. 91333206, 61274062, and 61774077), Guangzhou Science and Technology Planning Project (No. 201804010295), National Undergraduate Innovative and Entrepreneurial Training Program (No. 201810561016), Research and Development Program in Key Areas of Guangdong Province (2019B1515120073, 2019B090921002), Science and Technology Planning Project of Guangdong Province of China (2020A1414010036), and the Guangzhou Key Laboratory of Vacuum Coating Technologies and New Energy Materials Open Projects Fund (KFVE20200006). We would like to give our thanks to Songwei Liu, from the department of electronic engineering of the Chinese University of Hong Kong, who helped to revise this manuscript.

Conflicts of Interest: The authors declare no conflict of interest.

\section{References}

1. Biondi, M.; Choi, M.J.; Ouellette, O.; Baek, S.W.; Todorovic, P.; Sun, B.; Lee, S.; Wei, M.; Li, P.; Kirmani, A.R.; et al. A Chemically Orthogonal Hole Transport Layer for Efficient Colloidal Quantum Dot Solar Cells. Adv. Mater. 2020, 32, 1906199. [CrossRef]

2. Xu, J.; Voznyy, O.; Liu, M.; Kirmani, A.R.; Walters, G.; Munir, R.; Abdelsamie, M.; Proppe, A.H.; Sarkar, A.; Arquer, F.P.; et al. 2D matrix engineering for homogeneous quantum dot coupling in photovoltaic solids. Nat. Nanotechnol. 2018, 13, 456-462. [CrossRef]

3. Mcdonald, S.A.; Konstantatos, G.; Zhang, S.; Cyr, P.W.; Klem, E.J.D.; Levina, L.; Sargent, E.H. Solution-processed PbS quantum dot infrared photodetectors and photovoltaics. Nat. Mater. 2005, 4, 138. [CrossRef]

4. Luther, J.M.; Law, M.; Beard, M.C.; Song, Q.; Reese, M.O.; Ellingson, R.J.; Nozik, A.J. Schottky Solar Cells Based on Colloidal Nanocrystal Films. Nano Lett. 2008, 8, 3488-3492. [CrossRef] [PubMed]

5. Lu, K.; Wang, Y.; Liu, Z.; Han, L.; Shi, G.; Fang, H.; Chen, J.; Ye, X.; Chen, S.; Yang, F.; et al. High-Efficiency PbS Quantum-Dot Solar Cells with Greatly Simplified Fabrication Processing via "Solvent-Curing". Adv. Mater. 2018, 30, 1707572. [CrossRef] [PubMed]

6. Aqoma, H.; Imran, L.F.; Muhibullah, A.M.; Hadmojo, W.T.; Do, Y.R.; Jang, S. Efficient Hybrid Tandem Solar Cells Based on Optical Reinforcement of Colloidal Quantum Dots with Organic Bulk Heterojunctions. Adv. Energy Mater. 2020, 10, 1903294. [CrossRef]

7. Kokal, R.K.; Raavi, S.S.; Deepa, M. Quantum Dot Donor-Polymer Acceptor Architecture for a FRET-Enabled Solar Cell. ACS Appl. Mater. Interfaces 2019, 11, 18395-18403. [CrossRef] [PubMed]

8. Wang, L.; Wang, Y.; Jia, Y.; Liu, X.; Liu, T.; Fu, T.; Li, J.; Weng, B.; Zhang, X.; Liu, Y. Manipulation of Phase-Transfer LigandExchange Dynamics of PbS Quantum Dots for Efficient Infrared Photovoltaics. J. Phys. Chem. C 2019, 123, 30137-30144. [CrossRef] 
9. Mandal, D.; Goswami, P.N.; Rath, A.K. Thiol and Halometallate, Mutually Passivated Quantum Dot Ink for Photovoltaic Application. ACS Appl. Mater. Interfaces 2019, 11, 26100-26108. [CrossRef]

10. Becker-Koch, D.; Siguan, M.A.; Lami, V.; Paulus, F.; Xiang, H.; Chen, Z.; Vaynzof, Y. Ligand Dependent Oxidation Dictates the Performance Evolution of High Efficiency PbS Quantum Dot Solar Cells. Sustain. Energy Fuels 2020, 4, 108-115. [CrossRef]

11. Balazs, D.M.; Loi, M.A. Lead-Chalcogenide Colloidal-Quantum-Dot Solids: Novel Assembly Methods, Electronic Structure Control, and Application Prospects. Adv. Mater. 2018, 30, 180082. [CrossRef]

12. Debnath, R.; Bakr, O.; Sargent, E.H. Solution-processed colloidal quantum dot photovoltaics: A perspective. Energy Environ. Sci. 2011, 4, 4870-4881. [CrossRef]

13. Kramer, I.J.; Sargent, E.H. Colloidal Quantum Dot Photovoltaics: A Path Forward. ACS Nano 2011, 5, 8506-8514. [CrossRef] [PubMed]

14. Murray, C.B.; Kagan, C.R.; Bawendi, M.G. Synthesis and characterization of monodisperse nanocrystals and close-packed nanocrystal assemblies. Annu. Rev. Mater. Sci. 2000, 30, 545-610. [CrossRef]

15. Wu, R.F.; Yang, Y.H.; Li, M.Z.; Qin, D.H.; Zhang, Y.D.; Hou, L.T. Solvent Engineering for High-Performance PbS Quantum Dots Solar Cells. Nanomaterials 2017, 7, 201. [CrossRef]

16. Shi, G.; Wang, Y.; Liu, Z.; Han, L.; Liu, J.; Wang, Y.; Lu, K.; Chen, S.; Ling, X.; Li, Y.; et al. Stable and Highly Efficient PbS Quantum Dot Tandem Solar Cells Employing a Rationally Designed Recombination Layer. Adv. Energy Mater. 2017, 7, 1602667. [CrossRef]

17. Yang, F.; Xu, Y.; Gu, M.; Zhou, S.; Wang, Y.; Lu, K.; Liu, Z.; Ling, X.; Zhu, Z.; Chen, J.; et al. Synthesis of cesium-doped $\mathrm{ZnO}$ nanoparticles as an electron extraction layer for efficient $\mathrm{PbS}$ colloidal quantum dot solar cells. J. Mater. Chem. A 2018, 6, 17688-17697. [CrossRef]

18. Cao, Y.; Stavrinadis, A.; Lasanta, T.; So, D.; Konstantatos, G. The role of surface passivation for e-cient and photostable PbS quantum dot solar cells. Nat. Energy 2016, 1, 1-6. [CrossRef]

19. Wang, Y.; Lu, K.; Han, L.; Liu, Z.; Shi, G.; Fang, H.; Chen, S.; Wu, T.; Yang, F.; Gu, M.; et al. In Situ Passivation for Efficient PbS Quantum Dot Solar Cells by Precursor Engineering. Adv. Mater. 2018, 30, 1704871. [CrossRef]

20. Lp, A.H.; Thon, S.M.; Hoogland, S.; Voznyy, O.; Zhitomirsky, D.; Debnath, R.; Levina, L.; Rollny, L.R.; Fischer, A.; Kemp, K.W.; et al. Hybrid passivated colloidal quantum dot solids. Nat. Nanotechnol. 2012, 7, 577.

21. Yuan, M.; Liu, M.; Sargent, E.H. Colloidal quantum dot solids for solution-processed solar cells. Nat. Energy 2016, 1, 1-9. [CrossRef]

22. Lan, X.; Voznyy, O.; Arquer, F.P.; Liu, M.; Xu, J.; Proppe, A.H.; Walters, G.; Fan, F.; Tan, H.; Liu, M.; et al. 10.6\% Certified Colloidal Quantum Dot Solar Cells via Solvent-Polarity-Engineered Halide Passivation. Nano Lett. 2016, 16, 4630-4634. [CrossRef] [PubMed]

23. Sun, B.; Vafaie, M.; Levina, L.; Wei, M.Y.; Dong, Y.T.; Gao, Y.J.; Kung, H.T.; Biodi, M.; Proppe, A.H.; Chen, B.; et al. Ligand-Assisted Reconstruction of Colloidal Quantum Dots Decreases Trap State Density. Nano Lett. 2020, 3, 31. [CrossRef]

24. Azmi, R.; Aqoma, H.; Tantyo, W.H.; Yun, J.M.; Yoon, S.; Kim, K.; Do, Y.R.; Oh, S.H.; Jang, S.Y. Low-Temperature-Processed 9\% Colloidal Quantum Dot Photovoltaic Devices through Interfacial Management of $\mathrm{p}-\mathrm{n}$ Heterojunction. Adv. Energy Mater. 2016, 6, 1502146. [CrossRef]

25. Fan, J.Z.; Croix, A.D.; Yang, Z.; Howard, E.; Quintero-Bermudez, R.; Levina, L.; Jenkinson, N.M.; Spear, N.J.; Li, Y.; Ouellette, O.; et al. Ligand cleavage enables formation of 1,2ethanedithiol capped colloidal quantum dot solids. Nanoscale 2019, 11, 10774-10781. [CrossRef] [PubMed]

26. Wang, Y.; Liu, Z.; Hou, N.; Li, F.; Gu, M.; Ling, X.; Zhang, Y.; Liu, K.; Han, L.; Fang, H.; et al. Room-temperature direct synthesis of semi-conductive PbS nanocrystal inks for optoelectronic applications. Nat. Commun. 2019, 10, 5136. [CrossRef] [PubMed]

27. Yang, Y.H.; Zhao, B.F.; Gao, Y.P.; Liu, H.; Tian, Y.Y.; Qin, D.H.; Wu, H.B.; Huang, W.B.; Hou, L.T. Novel Hybrid Ligands for Passivating PbS Colloidal Quantum Dots to Enhance the Performance of Solar Cells. Nano-Micro Lett. 2015, 7, 325. [CrossRef] [PubMed]

28. Kim, H.; Gilmore, C.M.; Horwitz, J.S.; Murata, A.P.; Kushto, G.P.; Schlaf, R.; Kafafi, Z.H.; Chrisey, D.B. Transparent conducting aluminum-doped zinc oxide thin films for organic light-emitting devices. Appl. Phys. Lett. 2000, 76, 259. [CrossRef]

29. Lan, X.; Voznyy, O.; Kiani, A.; Arquer, F.P.; Abbas, A.S.; Kim, G.H.; Liu, M.; Yang, Z.; Walters, G.; Xu, J.; et al. Passivation Using Molecular Halides Increases Quantum Dot Solar Cell Performance. Adv. Mater. 2015, 28, 299-304. [CrossRef]

30. Stubhan, T.; Oh, H.; Pinna, L.; Krantz, J.; Litzov, I.; Brabec, C.J. Inverted organic solar cells using a solution processed aluminumdoped zinc oxide buffer layer. Organ. Electron. 2011, 12, 1539-1543. [CrossRef]

31. Liu, H.; Tang, J.; Kramer, I.J.; Debnath, R.; Koleilat, G.I.; Wang, X.H.; Fisher, A.; Li, R.; Brzozowski, L.; Levina, L.; et al. Electron Acceptor Materials Engineering in Colloidal Quantum Dot Solar Cells. Adv. Mater. 2011, 23, 3832-3837. [CrossRef] [PubMed]

32. Choi, M.J.; de Arquer, F.P.G.; Proppe, A.H.; Seifitokaldani, A.; Choi, J.; Kim, J.; Baek, S.W.; Liu, M.; Sun, B.; Biondi, M.; et al. Cascade surface modification of colloidal quantum dot inks enables efficient bulk homojunction photovoltaics. Nat. Commun. 2020, 11, 103. [CrossRef] [PubMed]

33. Murdoch, G.B.; Hinds, S.; Sargent, E.H.; Tsang, S.W.; Mordoukhovski, L.; Lu, Z.H. Aluminum doped zinc oxide for organic photovoltaics. Appl. Phys. Lett. 2009, 94, 213301. [CrossRef]

34. Schulze, K.; Maennig, B.; Leo, K.; Tomita, Y.; May, C.; Hupkes, J.; Brier, E.; Reinold, E.; Bauerie, P. Organic solar cells on indium tin oxide and aluminum doped zinc oxide anodes. Appl. Phys. Lett. 2007, 91, 073521. [CrossRef] 
35. Eisner, F.; Seitkhan, A.; Han, Y.; Khim, D.; Yengel, E.; Kirmani, A.R.; Xu, J.; Arquer, F.P.; Sargent, E.H.; Amassian, A.; et al. Solution-Processed $\operatorname{In}_{2} \mathrm{O}_{3} / \mathrm{ZnO}$ Heterojunction Electron Transport Layers for Efficient Organic Bulk Heterojunction and Inorganic Colloidal Quantum-Dot Solar Cells. Sol. RRL 2018, 2, 1800076. [CrossRef]

36. Mei, X.; Wu, B.; Guo, X.; Liu, X.; Rong, Z.; Liu, S.; Chen, Y.; Qing, D.; Xu, W.; Hou, L.; et al. Efficient CdTe Nanocrystal/TiO2 Hetero-Junction Solar Cells with Open Circuit Voltage Breaking $0.8 \mathrm{~V}$ by Incorporating A Thin Layer of CdS Nanocrystal. Nanomaterials 2018, 8, 614. [CrossRef]

37. Hu, L.; Li, D.B.; Gao, L.; Tan, H.; Chen, C.; Li, K.; Li, M.; Han, J.B.; Song, H.; Liu, H.; et al. Graphene Doping Improved Device Performance of ZnMgO/PbS Colloidal Quantum Dot Photovoltaics. Adv. Funct. Mater. 2016, 26, 1899-1907. [CrossRef]

38. Liu, S.; Liu, W.; Heng, J.; Zhou, W.; Chen, Y.; Wen, S.; Qin, D.; Hou, L.; Xu, H. Solution-Processed Efficient Nanocrystal Solar Cells Based on CdTe and CdS Nanocrystals. Coatings 2018, 8, 26. [CrossRef]

39. Chuang, C.M.; Brown, P.R.; Bulović, V.; Bawendi, M.G. Improved performance and stability in quantum dot solar cells through band alignment engineering. Nat. Mater. 2014, 13, 796. [CrossRef] 